\title{
Ecologia reprodutiva de Nyctanassa violacea, Egretta thula e Egretta caerulea no ninhal do rio Pedreira, Santa Catarina
}

\author{
Giulia Caroline Bisinela * \\ Tiago Ramos de Andrade \\ Marta Jussara Cremer \\ Universidade da Região de Joinville \\ Rua Paulo Malschitzki, 10, CEP 89219-710, Joinville - SC, Brasil \\ * Autor para correspondência \\ giubis@yahoo.com.br
}

\section{Resumo}

Este estudo teve por objetivo caracterizar o ninhal do rio Pedreira e estimar o sucesso reprodutivo das espécies do local. O local de estudo compreendeu o manguezal da desembocadura do rio Pedreira, localizado ao lado do porto de São Francisco do Sul. As amostragens foram realizadas semanalmente durante o ciclo reprodutivo das aves, tendo início no mês de agosto de 2011 e término no mês de março de 2012. Foram quantificados no total 210 ninhos, sendo 60 de Nyctanassa violacea e 150 de Egretta spp. A formação da colônia teve início no fim do inverno e encerrou no início do outono, permanecendo com maior atividade entre setembro e dezembro. O sucesso de eclosão foi muito semelhante entre as espécies, sendo 49\% para $N$. violacea e 50\% para Egretta spp. A sobrevivência dos filhotes foi maior para N. violacea, com 32\%, quando comparada com Egretta spp. que teve $24 \%$ de sucesso de sobrevivência.

Palavras-chave: Colônia reprodutiva; Sobrevivência; Sucesso reprodutivo

\section{Abstract}

Breeding ecology of Nyctanassa violacea, Egretta thula and Egretta caerulea nesting grounds in the Pedreira River, Santa Catarina State. This study aimed to characterize the Pedreira River breeding colony of wading birds and to estimate the breeding success of the species in this area. The study area included the mangrove in the Pedreira River, located next to the port of São Francisco do Sul harbor. Surveys were made weekly during the reproductive cycle of the birds, starting in August 2011 and ending in March of 2012. A total of 210 nests were recorded, which included 60 of Nyctanassa violacea and 150 of Egretta spp. The colony began in late winter and ended in early fall, with greater activity occurring between September and December. Hatching success was very similar between the species, with $49 \%$ for $N$. violacea and $50 \%$ for Egretta spp. The survival rate of the pups was higher for $N$. violacea with 32\%, compared with Egretta spp. with $24 \%$ survival.

Key words: Breeding success; Colonial Breeding; Survival 


\section{Introdução}

As aves aquáticas são aquelas ecologicamente dependentes das áreas úmidas continentais, litorâneas ou costeiras, constituindo-se um importante elo nas relações tróficas desses ecossistemas. Sua diversidade e abundância estão diretamente associadas às diferentes características dos ambientes onde ocorrem, como a área disponível, a profundidade da coluna d'água, as flutuações de suas condições físico-químicas, a estrutura e composição da vegetação e a disponibilidade de recursos (WIENS, 1989; GREEN; FIGUEROLA, 2003).

A reprodução colonial é característica das aves aquáticas e está relacionada a fatores como melhor eficiência na procura por alimento, à estratégia de saciar o predador (definição segundo WARNOCK et al., 2001) e às interações sociais favorecidas em ambiente colonial (COULSON, 2001; SICK, 2001; RICKLEFS, 2003). Essas colônias podem variar de dezenas a milhares de indivíduos (JOSENS et al., 2009).

A reprodução de aves em manguezais tem grande relação com a estrutura da vegetação, sendo esta característica de vital importância para as espécies que utilizam e constróem seus ninhos em diferentes estratos da vegetação (JOSENS et al., 2009; RECHETELO, 2009). Entretanto, o principal fator envolvido na escolha dos estuários pelas aves está relacionado a grande disponibilidade de alimento nestes ambientes (SILVA, 2008).

Aves com nidificação colonial são particularmente vulneráveis aos distúrbios humanos (POOLE, 1981). Como resposta às perturbações, observa-se o abandono do ninho, a redução no recrutamento e na construção de novos ninhos, o aumento da predação e até mesmo o abandono da colônia, ocasionando assim, um baixo sucesso reprodutivo. Essas respostas aos distúrbios humanos variam de acordo com o estágio de nidificação, tipo de distúrbio e espécie em questão (POOLE, 1981; BOERSMA et al., 2001).

Os manguezais comportam uma avifauna característica e com espécies restritas a estes habitats (ARAUJO et al., 2006). Apesar disso, poucos são os estudos no Brasil relacionados à comunidade de aves nestes ambientes (PERIQUITO et al., 2008). Para a região sudeste do Brasil, principalmente em Santos e Cubatão, destacam-se os estudos de Silva e Silva e Olmos (2007), para avifauna dos manguezais, e Olmos e Silva e Silva (2003), para ninhais da região, incluindo áreas reprodutivas muito próximas a zonas urbanas. $\mathrm{O}$ estudo com ninhais para a região Nordeste pode ser encontrado em Matos (1996) e para a região sul em Rechetelo (2009) no Paraná. Para o estado de Santa Catarina, no estuário da baía da Babitonga, onde fica localizado o manguezal do rio Pedreira, destaca-se a importância dos estudos de Grose (2012), Fink et al. (2011) e Grose et al. (2011a).

O ninhal do rio Pedreira, na baía da Babitonga, está situado ao lado de um grande porto de cargas, com grande fluxo de embarcações, ruídos constantes, despejo de resíduos industriais e movimentação de pessoas. Nesse sentido, é importante conhecer a biologia reprodutiva das aves que dependem do ninhal, para avaliar o efeito destes impactos sobre o sucesso reprodutivo das aves.

Este estudo visa caracterizar o ninhal existente na desembocadura do rio Pedreira, e estimar o sucesso reprodutivo nas diferentes fases de desenvolvimento. Com isso, espera-se gerar subsídios para a conservação da área e ampliar o conhecimento sobre as espécies envolvidas.

\section{Material e Métodos}

\section{Área de estudo}

A baía da Babitonga localiza-se na porção norte do litoral de Santa Catarina $\left(26^{\circ} 02^{\prime}-26^{\circ} 28^{\prime}\right.$ 'S e $48^{\circ} 28^{\prime}$ $48^{\circ} 50^{\prime} \mathrm{W}$ ) e é contornada em sua porção noroeste pela unidade geomorfológica da Serra do Mar e a sudeste pela ilha de São Francisco do Sul (Figura 1). A baía comporta a última grande formação de manguezal do hemisfério sul, constituindo o mais importante estuário do estado (IBAMA, 1998). Tem-se mostrado uma importante área de reprodução de aves aquáticas, contribuindo para o ciclo de vida das espécies (FINK et al., 2011; GROSE et al., 2011b). A região também é muito utilizada pelas aves aquáticas para alimentação e descanso (CREMER; GROSE, 2010). 
FIGURA 1: Brasil, norte de Santa Catarina (A), baia da Babitonga (B). Localização da área de de estudos marcada com um círculo (C). $\left(26^{\circ} 14 ' 25,06^{\prime \prime} \mathrm{S}-48^{\circ} 38^{\prime} 15,27^{\prime \prime} \mathrm{O}\right)$. A desembocadura do rio Pedreira, onde foram observados os ninhos junto à margem, seguindo o transecto $(\mathrm{E}=$ entrada; $\mathrm{S}=$ saída) situa-se entre o porto de São Francisco do Sul e seu centro histórico.
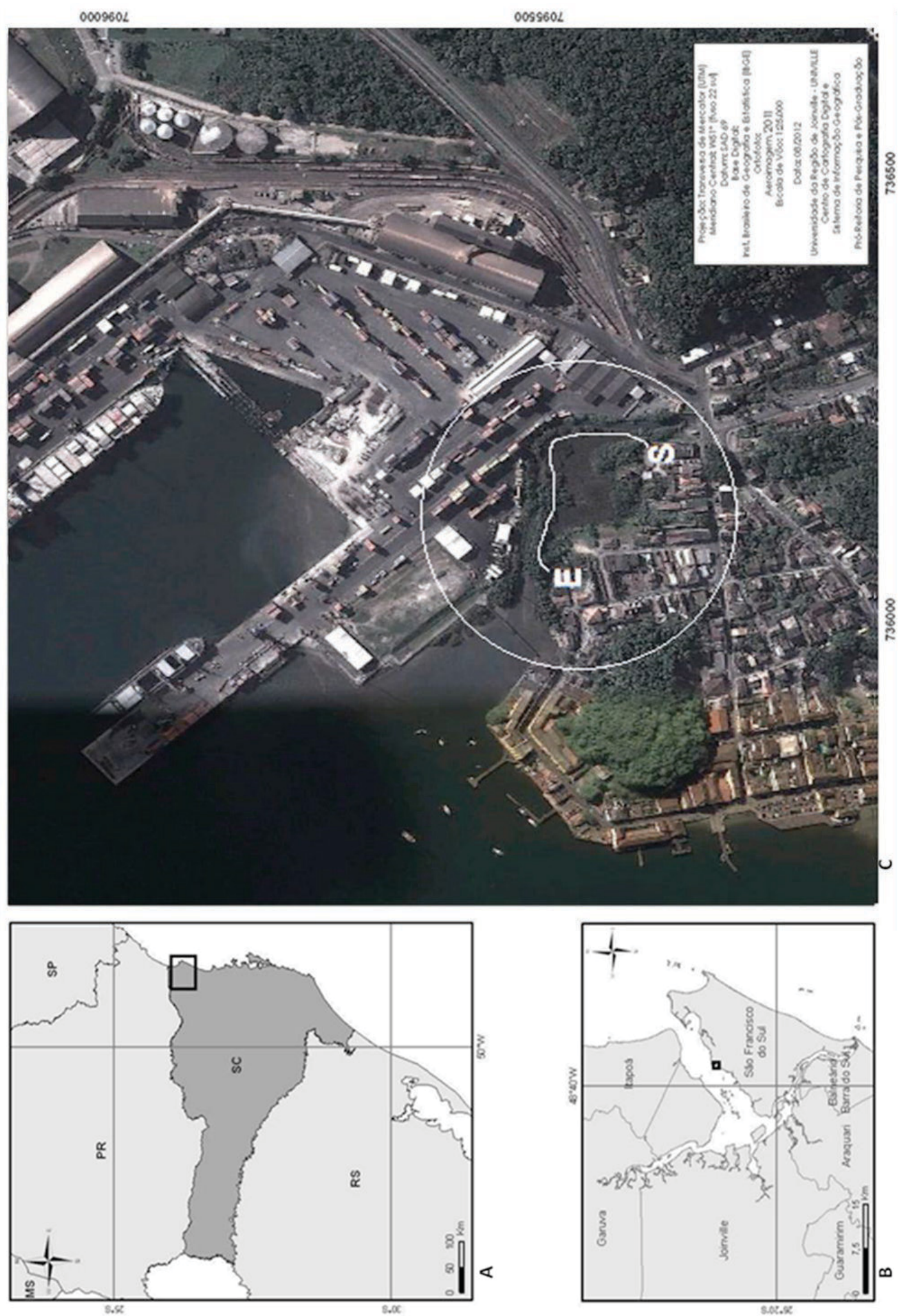
$\mathrm{O}$ estudo foi realizado na desembocadura do rio Pedreira (26ำ $\left.14^{\prime} 25,06^{\prime \prime} S-48^{\circ} 38^{\prime} 15,27^{\prime \prime} \mathrm{O}\right)$, situada entre o Terminal Portuário Santa Catarina (TESC) e o centro histórico de São Francisco do Sul (Figura 1). O rio atravessa a cidade e desemboca na baía da Babitonga e encontra-se bastante degradado na maior parte de seu percurso. Junto à desembocadura, suas margens são cobertas por remanescentes de manguezal. As margens apresentam sedimento lodoso e tendência de maior concentração de matéria orgânica na desembocadura, por ser diretamente influenciada pela pluma fluvial existente (FRISANCO, 2007). A intensa pressão antrópica sobre o rio Pedreira acontece em boa parte de seu percurso, por causa do despejo de esgoto, lixo e crescimento urbano em ambas as margens, além da presença do porto junto à desembocadura.

\section{Coleta de dados}

Foram realizados semanalmente amostragens a pé na desembocadura do rio Pedreira, entre 28 de julho de 2011 e 26 de agosto de 2011, junto à margem do terminal portuário para identificar as espécies e registrar a ocorrência de comportamentos de corte que indicassem o início da reprodução das aves. A partir da construção dos primeiros ninhos, as amostragens passaram a ser realizadas na área interna do manguezal, na margem oposta, situada ao lado do centro histórico da cidade. Essas amostragens ocorreram entre 26 de agosto de 2011 e 8 março de 2012.

As árvores com ninhos foram marcadas com um lacre numerado, identificadas quanto à espécie e medidas no seu perímetro à altura do peito (PAP) (circunferência do tronco à altura do peito) com auxílio de fita métrica. Os dados de PAP foram convertidos posteriormente para diâmetro (DAP $=\mathrm{PAP} / \pi)($ JOLY et al., 2012). A altura do ninho foi estimada visualmente usando como referência uma haste telescópica com $3 \mathrm{~m}$ de comprimento. Os ninhos não foram marcados individualmente, mas quantificados e monitorados a partir da identificação da árvore. A cada amostragem foi registrado o número de ninhos para cada árvore marcada e o número de ovos e filhotes de cada ninho. Todo o ciclo reprodutivo foi acompanhado, desde a construção dos ninhos até a saída dos juvenis da colônia. Para visualizar os ovos e filhotes nos ninhos utilizou-se uma haste telescópica com um espelho na extremidade com capacidade de extensão de até $3 \mathrm{~m}$, que, somada à altura do pesquisador com o braço erguido, totalizou, em média, $5 \mathrm{~m}$. Em alguns casos foi necessário subir nas árvores para visualizar o ninho.

A cada amostragem o conteúdo dos ninhos foi classificado considerando-se cinco estágios, com base nas definições apresentadas por Gianuca (2010): a) ovo b) filhote I (1 semana de vida) - definido como filhote recém-eclodido, que não excursiona pelos galhos nem responde à presença dos pesquisadores; c) filhote II ( 2 a 4 semanas de vida) - definido como mais desenvolvido, que já sai do ninho e responde à presença humana, com idade e características suficientes para fins de identificação e diferenciação no caso de espécies muito semelhantes; d) juvenil I (4 a 6 semanas de vida) - definido por um tamanho e plumagem mais desenvolvidos, capaz de realizar pequenos voos, mas ainda dependente do ninho e da alimentação fornecida pelos pais; e) juvenil II (a partir de 7 semanas de vida) definido como jovem completo, independente do ninho, com plumagem desenvolvida e capacidade total de voo e forrageio independente.

Como os ninhos não foram monitorados individualmente, o sucesso reprodutivo foi analisado por árvore, somando-se os dados de todos os ninhos de cada táxon. Foi calculado o sucesso por árvore para cada táxon, considerando-se a eclosão, o estágio de filhote I e de filhote II (GIANUCA, 2010). A partir do estágio de filhote II, os animais começam a se movimentar agilmente entre os galhos e abandonam os ninhos frente à aproximação humana, não sendo mais possível associá-los aos ninhos ou às árvores monitoradas. Por este motivo, não foi possível avaliar o sucesso para os estágios juvenil I e juvenil II (GIANUCA, 2010).

O sucesso de eclosão por árvore foi estimado utilizando-se a expressão: número de filhotes I/número de ovos (x100). Para o sucesso reprodutivo do estágio filhote II por árvore a expressão utilizada foi: número de filhotes II/número de ovos (x100) (GIANUCA, 2010). A sobrevivência a cada fase de desenvolvimento também foi calculada, segundo a metodologia de Gianuca (2010). Para a sobrevivência, foi utilizada a expressão: número de filhotes em estágio II/número 
de filhotes em estágio I (x100), para cada táxon. Para estimar o número de animais reprodutores, o número de ninhos foi multiplicado por dois, considerando-se o sistema monogâmico de reprodução das espécies em questão (razão 1:1) e a premissa de que cada casal teria construído um único ninho (GROSE, 2012).

Para avaliar a relação entre o número de ninhos e a estrutura da árvore, a altura e o DAP foram divididos em classes, sendo sete classes para DAP $(1,4 \mathrm{~cm}$ a 24,4 $\mathrm{cm}$, com intervalos de $3,2 \mathrm{~cm})$ e seis para altura $(3,5 \mathrm{~m}$ a $10 \mathrm{~m}$, com intervalos de $1 \mathrm{~m}$ ). Para analisar a correlação entre a altura e o DAP da árvore com o número de ninhos por árvore, foi utilizado a correlação linear de Spearman, com nível de significância de 95\%. As análises foram realizadas no programa Statistica v.7.0.

\section{Resultados}

Foram contabilizados 60 ninhos de $N$. violacea e 150 de Egretta spp. Devido à semelhança entre os ninhos e o afastamento, do ninho, de adultos de E. thula e E. caerulea durante a realização das amostragens, não foi possível diferenciar os ninhos dessas espécies nos estágios iniciais. Por este motivo, neste caso, as análises foram realizadas em nível de gênero. Estimou-se uma população reprodutiva de, pelo menos, 420 indivíduos, dos quais 120 de $N$. violacea e 300 de Egretta spp.
O período reprodutivo na colônia foi de agosto de 2011 a março de 2012 (Figura 2). A primeira espécie a ocupar a colônia foi $N$. violacea, com a presença de ovos no final de agosto. Egretta thula e E. caerulea iniciaram a ocupação da colônia simultaneamente, iniciando sua atividade reprodutiva em setembro e encerrando-a entre os meses de fevereiro e março.

Os ovos de $N$. violacea são de coloração azul esverdeado e os de Egretta spp. azul claro. O número de ovos para todas as espécies variou de 1 a 3 . Foi verificado um único ninho de $N$. violacea contendo 4 ovos e um único ninho de Egretta spp. com 4 ovos. As espécies de Egretta totalizaram 318 ovos, 160 filhotes I, 76 filhotes II, 55 juvenis I e 44 juvenis II. Para $N$. violacea, foram quantificados 134 ovos, 66 filhotes I, 43 filhotes II, 39 juvenis I e 18 juvenis II. Foi observado apenas um caso de comportamento de exclusão do filhote mais novo pelo mais velho em um ninho de $N$. violacea.

O período de maior postura de $N$. violacea foi em setembro, e um segundo pulso reprodutivo foi observado entre outubro e novembro, mas com menor quantidade de ovos (Figura 3). Egretta spp. também apresentaram um segundo pulso reprodutivo, que ocorreu entre dezembro e janeiro, mas com um número bem mais reduzido de ovos em relação ao primeiro (Figura 4). O pico de filhotes I foi em novembro, tanto para $N$. violacea quanto para Egretta spp. Filhotes em estágio II foram mais

FIGURA 2: Número total de ninhos de Nyctanassa violacea e Egretta spp. a cada mês mostrando o início e o término do período reprodutivo para cada táxon, registrado entre agosto/2011 e março/2012 no ninhal da desembocadura do rio Pedreira, baía da Babitonga, Santa Catarina, Brasil.

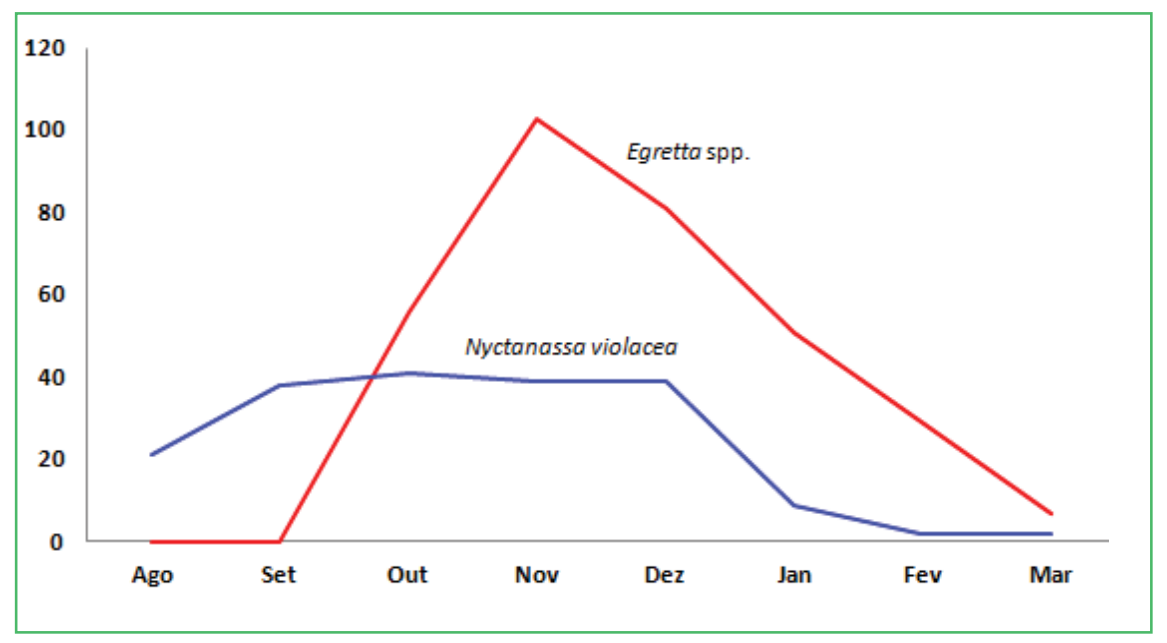


numerosos nos meses de novembro e dezembro para $N$. violacea e em dezembro para Egretta spp.

O sucesso de eclosão foi muito semelhante para os táxons e o sucesso dos filhotes até estágio II foi maior para $N$. violacea (Tabela 1). Quando analisada a sobrevivência por fase de desenvolvimento, a maior mortalidade para Egretta spp. ocorreu entre a fase de filhote estágio I para filhote estágio II do que entre ovo e filhote estágio I. A maior chance de sobrevivência de $N$. violacea foi entre a fase filhote I e a fase filhote II em comparação a transição entre a fase de ovo e a fase de filhote estágio I. Ou seja, a maior mortalidade para $N$. violacea ocorreu na fase de ovo e para Egretta spp. na fase de filhote estágio I (Tabela 2). O sucesso total da colônia, se consideradas todas as espécies somente até o estágio de filhote II, foi de $26 \%$. Contudo, após esse estágio ainda pode ocorrer perda de indivíduos.

Foram registrados ninhos em 49 árvores de duas, das três espécies de 'mangue' presentes na área de estudo: 48 em Avicennia schaueriana (mangue-preto) $\mathrm{e}$ 1 em Rhizophora mangle (mangue-vermelho). A altura das árvores que comportavam ninhos variou entre $3 \mathrm{e}$ $10 \mathrm{~m}$ (média $=6,11 \mathrm{~m}, \mathrm{DP}=1,95$ ) e o DAP entre $1,4 \mathrm{~cm}$ e 23,9 cm (média $=12 \mathrm{~cm}, \mathrm{DP}=5,06$ ). O maior número de ninhos construídos foi na classe 4 do DAP $(11,3$ a $14,5 \mathrm{~cm})(35 \%)$ para ambos os táxons considerados.

FIGURA 3: Número total de ovos, de filhotes em estágio I e filhotes em estágio II de Nyctanassa violacea a cada mês no ninhal da desembocadura do rio Pedreira, baía da Babitonga, Santa Catarina, Brasil, registrado entre agosto/2011 e março/2012.

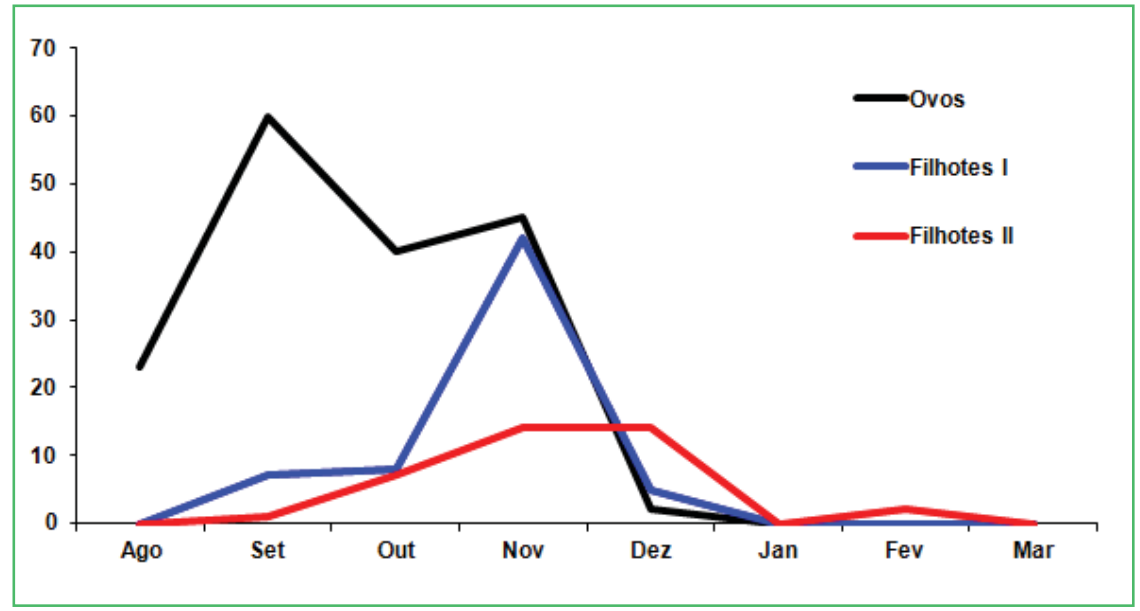

FIGURA 4: Número total de ovos, de filhotes em estágio I e filhotes em estágio II do gênero Egretta spp. a cada mês no ninhal da desembocadura do rio Pedreira, registrado entre agosto/2011 e março/2012.

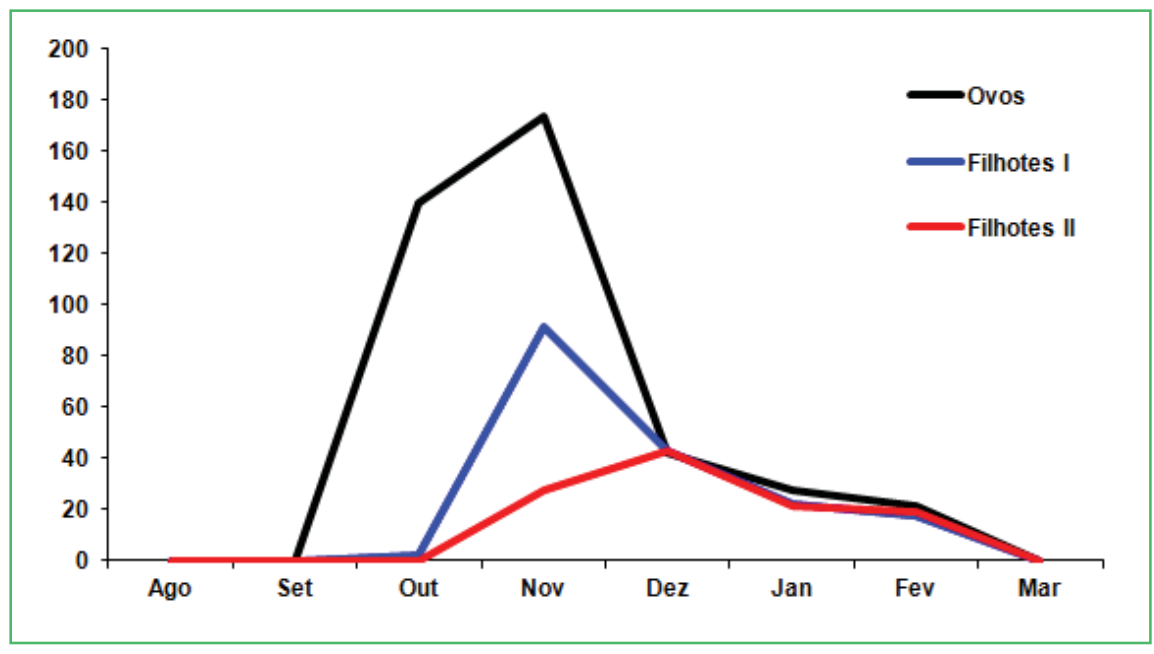


Na classe $6(17,9$ a 21,1 cm) não foram registrados ninhos de $N$. violacea (Figura 5). Com relação à altura da árvore, a classe 1 (3,4 a 4,5 m) foi a que apresentou maior número de ninhos construídos, representando $34 \%$ do total (Figura 6). Não foi verificada correlação significativa entre a altura da árvore e o número de ninhos ( $p=-0,19$ - correlação fraca negativa) e entre o DAP e o número de ninhos $(\mathrm{p}=0,29$ - correlação fraca positiva).

TABELA 1: Sucesso reprodutivo de eclosão e de filhote estágio II de Nyctanassa violacea e Egretta spp. no ninhal da desembocadura do rio Pedreira, baía da Babitonga, Santa Catarina, Brasil, registrado entre agosto/2011 e março/2012.

\begin{tabular}{ccc}
\hline \multirow{2}{*}{ Táxon } & \multicolumn{2}{c}{ Sucesso } \\
\cline { 2 - 3 } & Eclosão & Filhote II \\
\hline Nyctanassa violacea & $49 \%$ & $32 \%$ \\
Egretta spp. & $50 \%$ & $24 \%$ \\
\hline
\end{tabular}

TABELA2: Sobrevivência entre as fases de desenvolvimento para Nyctanassa violacea e Egretta spp. no ninhal da desembocadura do rio Pedreira, baía da Babitonga, Santa Catarina, Brasil, registrado entre agosto/2011 e março/2012 (segundo metodologia de GIANUCA, 2010).

\begin{tabular}{ccc}
\hline \multirow{2}{*}{ Táxon } & \multicolumn{2}{c}{ Fase } \\
\cline { 2 - 3 } & $\begin{array}{c}\text { Ovo para } \\
\text { filhote I }\end{array}$ & $\begin{array}{c}\text { Filhote I para } \\
\text { filhote II }\end{array}$ \\
\hline Nyctanassa violacea & $49 \%$ & $65 \%$ \\
Egretta spp. & $50 \%$ & $48 \%$ \\
\hline
\end{tabular}

\section{Discussão}

O início da estação reprodutiva pode estar associado ao período mais chuvoso do ano (MATOS, 1996; OLMOS et al., 2001) e de maior oferta de alimento. O período reprodutivo de $N$. violacea foi semelhante ao observado por Grose (2012) na ilha do Maracujá, também na baía da Babitonga, iniciando-se em agosto e estendendo-se até janeiro. Para E. caerulea, o período reprodutivo na mesma Ilha, de acordo com Grose (2012), foi distinto ao registrado no presente estudo.

FIGURA 5: Número de ninhos de Nyctanassa violacea e Egretta spp. em relação às seis categorias de diâmetro a altura do peito (DAP) no ninhal da desembocadura do rio Pedreira, baía da Babitonga, Santa Catarina, Brasil, registrado entre agosto/2011 e $\operatorname{março/2012.~}$

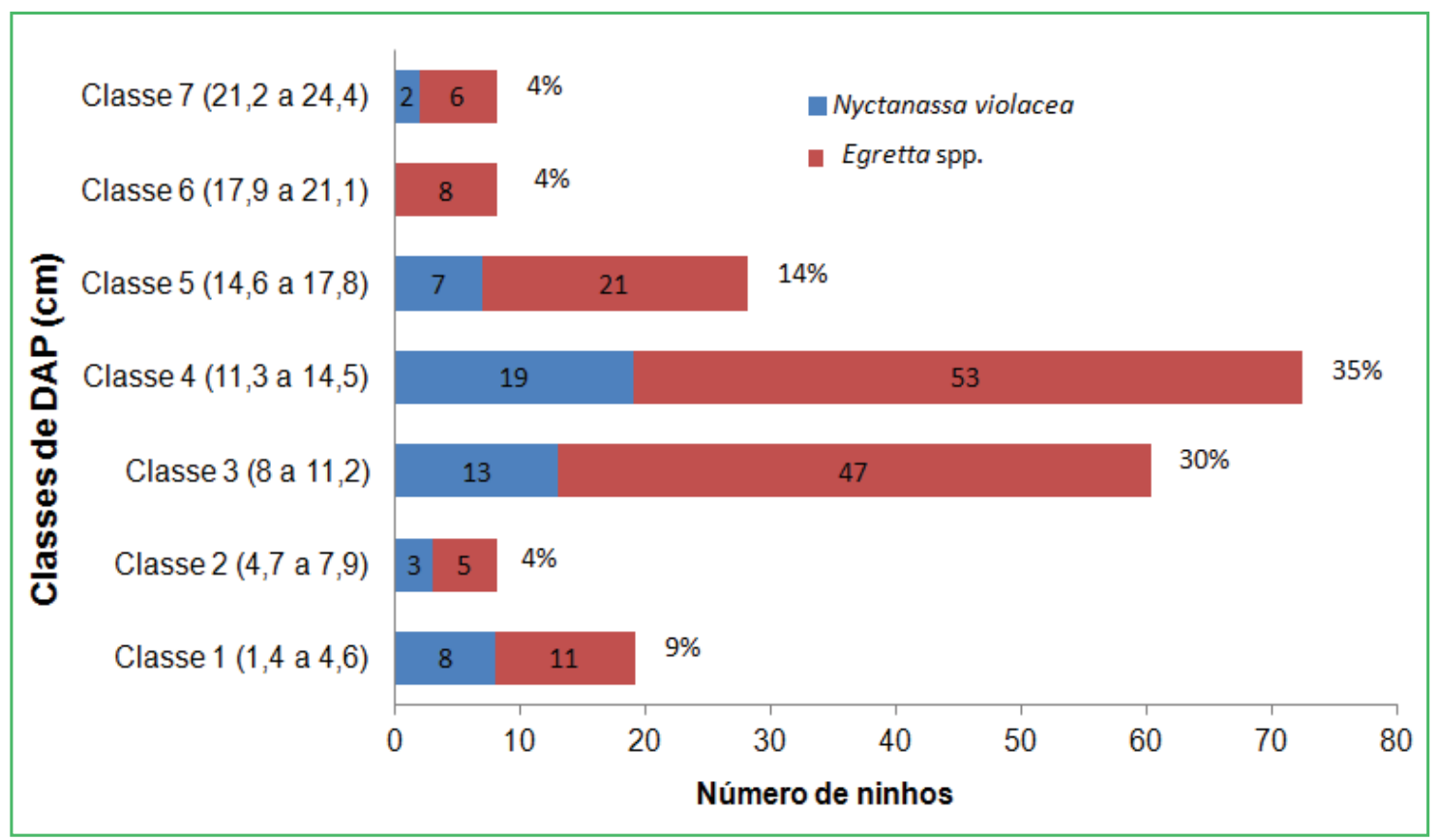


FIGURA 6: Número de ninhos de Nyctanassa violacea e Egretta spp. em relação às seis classes de altura da árvore no ninhal da desembocadura do rio Pedreira, baía da Babitonga, Santa Catarina, Brasil, registrado entre agosto/2011 e março/2012.

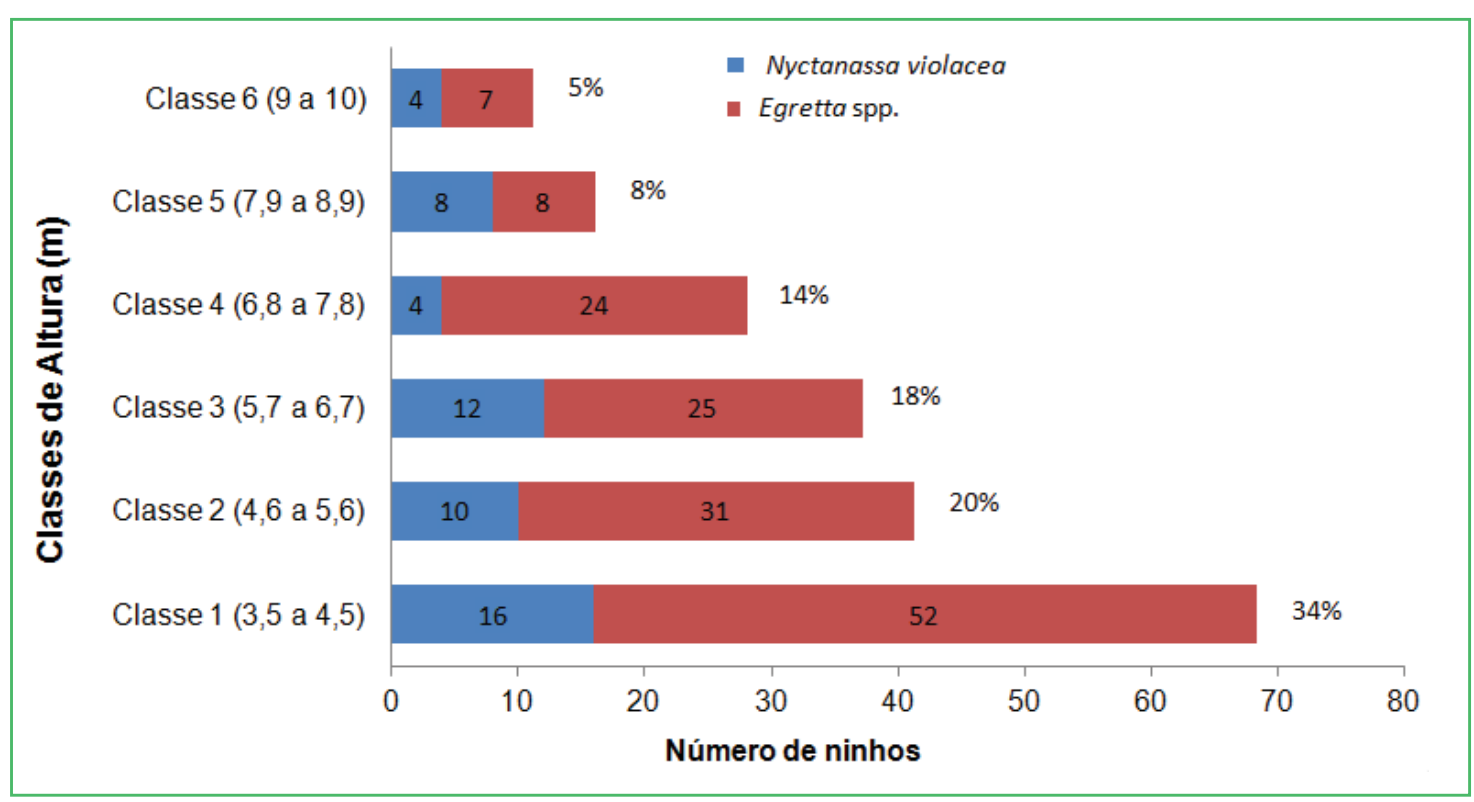

Segundo esse autor, a espécie iniciou a reprodução mais tarde no local, em novembro. O período reprodutivo de E. caerulea e E. thula foi semelhante ao registrado por Gianuca et al. (2012) no estuário da Lagoa dos Patos, Rio Grande do Sul. Para este autor, o período de atividade reprodutiva observado no estudo, corresponde ao padrão sazonal de reprodução de espécies da ordem Pelecaniformes, conhecido para regiões temperadas de ambos os hemisférios, nas quais a estação reprodutiva inicia no fim do inverno e se encerra no fim do verão (KUSHLAN; HANCOCK, 2005).

Alguns ninhais sincronizam a reprodução seguindo o ritmo do pulso de inundações anual. Para Silva et al. (2000) as espécies de garças que vivem no pantanal (MT), onde há períodos de vazante e cheia, chegam no ninhal em julho, onde as águas estão em um nível mais baixo. A espécie $N$. violacea foi capaz de chegar ao Rio Grande do Sul, em períodos de temperatura mais baixa e se reproduzir com sucesso, mas abandona a região aos primeiros sinais de resfriamento (GIANUCA; COSTA, 2007). Segundo Kushlan e Hancock (2005), de maneira geral, a temperatura local e as condições hidrológicas nas áreas de forrageio são os principais fatores que influenciam a sazonalidade da estação reprodutiva.
Segundo Olmos e Silva e Silva (2003), a disponibilidade de caranguejos é provavelmente, o fator que determina o período reprodutivo de $N$. violacea. Os autores citam que para a Baixada Santista, litoral do estado de São Paulo, o pico de filhotes entre novembro e dezembro pode estar relacionado ao período de maior atividade de Chasmagnathus granulata e Euruthium limosum, e também de Ucides cordatus, principal item alimentar da espécie (OLMOS; SILVA e SILVA, 2003; WUNDERLICH et al., 2008; RECHETELO, 2009). De acordo com Wunderlich et al. (2008), o período reprodutivo de $U$. cordatus na baía da Babitonga vai de novembro a março, coincidindo com o pico de filhotes I e II. A dieta de E. caerulea durante o período reprodutivo nas colônias Rio Morrão e Imigrantes (SP) é composto principalmente de caranguejos, dentre eles a espécie Aratus pisonii (OLMOS; SILVA e SILVA, 2003), que tem seus picos reprodutivos entre agosto e novembro, e janeiro a março para o estado (SALVI, 2002). Na baía da Babitonga, a maior densidade de A. pisonii foi registrado no verão (ALMEIDA, 2009), podendo novamente, o pico de filhotes estar associada à disponibilidade deste recurso alimentar, para o manguezal do Rio Pedreira.

A variação no número de ovos (1 a 3) por ninho registrada neste estudo foi a mesma verificada por 
Olmos e Silva e Silva (2003). Segundo esses autores, os filhotes eclodem em momentos diferentes, o que faz com o que o filhote do terceiro ovo seja menor e mais fraco, podendo ser empurrado pelos demais para fora do ninho (MATOS, 1996; NELSON; BAIRD, 2001). Apesar de o comportamento ter sido observado apenas uma vez neste estudo para $N$. violacea, ele é comum entre outras espécies de aves, como os socós-dominhocos (Nycticorax nycticorax), biguás (Phalacrocorax brasilianus), pelicanos (Pelecanidae) e atobás (Sulidae) (FREDERICHY, 2001; NELSON; BAIRD, 2001; OLMOS; SILVA e SILVA, 2003).

De acordo com Silva et al. (2000), a fase de ovos e filhotes é o período mais crítico de sobrevivência para várias espécies de aves aquáticas estudadas no ninhal Corutuba (MT), como Platalea ajaja (colheireiro), Ardea cocoi (garça-moura), Ardea alba (garça-bracagrande) e E. thula.

A estrutura dos ninhos também é fator decisivo para o sucesso nestas primeiras fases, principalmente no período de eclosão dos ovos. A construção de ninhos fortes e firmes pode contribuir para o maior sucesso dos filhotes de $N$. violacea, já que estes são mais resistentes a fatores climáticos, como fortes chuvas, ventanias e oscilações de maré. Poucos ninhos por árvore e ninhos construídos a menores altitudes, também diminuem os riscos de predação por predadores terrestres e aéreos (MATOS, 1996).

É comum a espécie $N$. violacea não abandonar o ninho, permanecendo nele mesmo na presença de seres humanos, o que reduz o estresse dos filhotes durante a realização das amostragens (MATOS, 1996). No caso de Egretta spp. os filhotes têm um comportamento de fuga diante de seres humanos, o que pode ocasionar grande estresse ou até mesmo sua queda do ninho. Por este motivo, os estudos de campo com este gênero em áreas reprodutivas devem ser realizados com muito cuidado e discrição.

Os percentuais de sucesso de eclosão e de filhotes até estágio II de ambos os táxons no rio Pedreira foram, na sua maioria, menores que os registrados em outras regiões. O sucesso de eclosão de $N$. violacea na ilha do Maracujá foi estimado em $73,5 \%$, e em $26,4 \%$ para filhotes em estágio II (GROSE, 2012). Grose et al. (2011a) determinaram um sucesso de $82 \%$ de eclosão e $32 \%$ para filhotes com até cinco semanas, na mesma ilha, para $N$. violacea e $N$. nycticorax. Matos (1996) registrou um sucesso de eclosão de $49,06 \%$ e e um sucesso reprodutivo de $62,5 \%$ para filhotes II, para $N$. violacea na ilha do Cajual (MA). Rechetelo (2009) estudou a espécie $N$. violacea no litoral do Paraná e registrou uma taxa de eclosão variando de $21,4 \%$ a $64,1 \%$. O menor sucesso na fase ovo é refletida por um desaparecimento mais expressivo dos ovos do que dos filhotes. Fatores como predação por animais aéreos e terrestres, assim como intempéries climáticas, podem influenciar nesta taxa (DUSI; DUSI, 1968).

Segundo Olmos e Silva e Silva (2003), 30\% a $60 \%$ do ninhos de E. caerulea produziu pelo menos um filhote que atingiu o estágio I e apenas um produziu três filhotes que chegaram à terceira semana de vida (filhote II), porém, essas porcentagens podem variar depedendo do ano e da colônia. Áreas reprodutivas podem ser afetadas por fênomes climáticos que variam de ano para ano, como por exemplo o El Niño, que afeta as correntes, a temperatura da água e a distribuição de peixes. A presença de outros indivíduos na área também é um fator determinante para a escolha do local, já que fornece o estímulo necessária para a reprodução (COULSON, 2001). Brooke (1986) acredita ainda que as variações intraespecíficas no crescimento dos filhotes e no sucesso do assentamento têm sido atribuídas à diferenças individuais no momento da colocação dos ovos dentro de um determinado ano, à idade e a experiência de criação dos pais, à qualidade individual, determinada geneticamente, e as diferenças na disponibilidade de alimentos entre colônias dentro de uma temporada (FRANK; BECKER, 1992). Desta forma, aves com reprodução colonial podem ajustar, a cada ano, o período e o tempo reprodutivo de acordo com as condições do meio (COULSON, 2001).

Analisando-se o sucesso nas diferentes fases de desenvolvimento, Gianuca (2010) registrou uma maior chance de sobrevivência na fase de filhote (54\%) que na fase de ovo (29\%) para Egretta spp. na Lagoa dos Patos, o que difere dos valores encontrados na presente pesquisa. Rechetelo (2009), nas três estações 
reprodutivas monitoradas no Parque Natural Municipal do Manguezal do Rio Perequê (PR), e Matos (1996) na ilha do Cajual (MA), também verificaram um maior sucesso na fase filhote que na fase ovo para $N$. violacea. Esta mesma tendência foi registrada no presente estudo, pois o período de incubação foi o que apresentou maior número de perdas. Para Matos (1996), a sobrevivência dos filhotes é maior que a dos ovos por fatores como: postura pequena de ovos, dos quais alguns ainda são perdidos. Por causa disso, os pais criam poucos filhotes e conseguem alimentar-los de forma satisfatória; tamanho reduzido da ninhada, que sugere um investimento maior dos pais em relação à prole; o comportamento agressivo dos filhotes em estágio II representando uma defesa contra predadores; e mobilidade dos filhotes, deslocando-se do ninho para locais mais seguros (GROSE, 2012).

As causas de mortalidade de ovos e filhotes podem ser variadas, mas entre as mais frequentes estão a predação e queda por ventos (OLMOS; SILVA e SILVA, 2003). Não foram observados predadores no rio Pedreira, embora seja muito provável que eventos de predação tenham acontecido. É possível que a queda seja a maior causa de mortalidade de filhotes e de perda de ovos no ninhal do rio Pedreira para o gênero Egretta. Isso pode estar relacionado ao comportamento dos filhotes de deixar do ninho já na segunda semana de vida, afugentados pela aproximação de pessoas, já que a área fica muito próxima a um centro urbano. Nessa fase os filhotes ainda não tem a resistência necessária e as quedas podem ser frequentes (OLMOS; SILVA e SILVA, 2003). A proximidade do porto e da cidade, com frequente movimentação de pessoas em torno na colônia, pode ter sido responsável por boa parte da mortalidade verificada no rio Pedreira. Segundo Olmos e Silva e Silva (2003), as garças apresentam um comportamento em que os filhotes mais velhos e fortes competem com os caçulas, que morrem na maioria das vezes. Isso contrasta com $N$. violacea, espécie na qual todos os filhotes tendem a atingir a idade de voo em condições favoráveis. Segundo O'Connor (1978), a explicação mais comum para a evolução deste padrão de redução de ninhada é que ele permite aos adultos um mecanismo de ajuste do tamanho da ninhada à disponibilidade de presa. Para o autor, quando o alimento é abundante todos os jovens são criados, mas quando é escasso, há competição entre os filhotes resultando em alimentação desigual, garantindo ao mais velho, maiores chances de sobrevivência.

Aves aquáticas, como predadoras de elevado nível na cadeia, acumulam inúmeros compostos químicos persistentes e não persistentes lançados no ambiente (BOSTAN et al., 2007) e, por isso, é razoável considerar a possível contribuição de contaminantes no sucesso reprodutivo e na sobrevivência dos filhotes (BURGER; GOCHFELD, 2001). Metais pesados podem interferir no sucesso reprodutivo, afetando a produção de ovos, o sucesso de eclosão e causando má formação (BOSTAN et al., 2007). Oliveira et al. (2006) demonstraram a biodisponibilidade de metais pesados na baía da Babitonga em praticamente toda a sua área e em todos os compartimentos (água, sedimento e organismos) e estações analisadas. Um dos pontos analisados foi o canal de acesso dos navios ao porto de São Francisco do Sul, que sofre influência da intensa atividade portuária, bem como dos efluentes domésticos do município, devido à precariedade do saneamento básico na cidade (OLIVEIRA et al., 2006). Neste ponto foram encontradas altas taxas de arsênio, chumbo, mercúrio e principalmente cádmio no sedimento, além de outros metais em menores proporções. Sabendo-se que as aves aquáticas se alimentam principalmente de organismos bentônicos e peixes, os contaminantes encontrados no sedimento e na água representam risco à saúde das populações, mesmo quando expostas a baixas concentrações, mas em períodos longos de exposição (OLIVEIRA et al., 2006). Dessa forma, é possível que muitas mortes de filhotes no rio Pedreira tenham sido causadas pelo contato com a poluição encontrada na área e em seus arredores.

Na ilha do Cajual (Maranhão), Matos (1996) registrou todos os ninhos de $N$. violacea em árvores do gênero Avicennia, mesmo com a presença de outros gêneros como Rhizophora e Laguncularia, assim como observado no ninhal do rio Pedreira. O DAP das árvores que comportavam ninhos variou de 3,8 a $11,8 \mathrm{~cm}$. A altura mínima das árvores que comportavam os ninhos foi de $2 \mathrm{~m}$ e a máxima de $5 \mathrm{~m}$, mas a maioria dos ninhos observados no estudo da autora, foi construído em 
árvores distintas; ou seja, somente um ninho por árvore. Nyctanassa violacea parece ter preferência por árvores de mangue, mesmo com a presença de outras espécies de árvores, como registrado por Grose (2012) na ilha do Maracujá, também na baía da Babitonga. Rechetelo (2009) verificou que das três espécies existentes no manguezal, duas ( $L$. racemosa e $R$. mangle) foram utilizadas como suporte de ninho de $N$. violacea, com um predomínio de ninhos construídos em $R$. mangle. De acordo com essa autora, considerando toda a variedade de espécies de árvores utilizadas para a nidificação de $N$. violacea ao longo de sua distribuição, a maior utilização de $R$. mangle pode ter ocorrido em virtude de sua estrutura arbórea e localização na área, e não de sua preferência por esta espécie arbórea. Assim como no presente estudo, Matos (1996) também verificou que muitos dos ninhos de $N$. violacea permaneceram intactos na ilha do Cajual, podendo ser reutilizados em uma próxima estação reprodutiva.

Em geral, as garças apresentaram ninhos mais altos que $N$. violacea. Os ninhos de E. caerulea podem apresentar variações na altura, dependendo do local onde se encontra a colônia (OLMOS; SILVA e SILVA, 2002). Duas colônias, no sudeste do Brasil, localizadas em uma área de manguezal bastante impactada pela poluição e atividades portuárias, foram estudadas por Olmos e Silva e Silva (2002). Na colônia do rio Saboó, dominada por $L$. racemosa, as garças nidificaram em alturas maiores que na colônia do rio Morrão, onde predominava a espécie $R$. mangle. Em duas colônias mistas, com E. caerulea e Eudocimus ruber (guarás), os ninhos de garça foram significativamente mais baixos na colônia do rio Saboó em comparação com ninhos de guarás, indicando uma preferência por árvores mais baixas (OLMOS; SILVA e SILVA, 2002). O número de ninhos por árvore no Saboó também foi muito menor do que no Morrão.

Apesar de reduzida, a área de estudo constitui a segunda maior colônia reprodutiva da baía da Babitonga, destacando-se a importância do local para as espécies avaliadas neste estudo (FINK, 2013). Os dados indicam que a estrutura da vegetação no manguezal do rio Pedreira não interferiu no número de ninhos construídos, ressaltando que, para o local, outros fatores ambientais podem ser mais determinantes na construção dos ninhos e crescimento dos filhotes, como a oferta e facilidade na obtenção de alimento. Por ser constantemente alvo de alterações e perturbações antrópicas, é necessário manter e aprofundar as pesquisas nesta área para avaliar com maior detalhe os impactos gerados pela presença do porto e da urbanização, a fim de planejar medidas de conservação para a área. Um maior conhecimento sobre o hábito de vida e a ecologia reprodutiva destas espécies e também de outras que venham a nidificar no local são urgentes, visto a importância das mesmas para o ecossistema no qual residem além de garantir o hábitat da avifauna que demonstra uma grande dependência desses ambientes.

\section{Agradecimentos}

Ao Fundo de Apoio à Pesquisa da Universidade da Região de Joinville, FAP/UNIVILLE, pelo suporte financeiro, e a todos que contribuíram para a realização deste estudo.

\section{Referências}

ALMEIDA, A. M. de. Distribuição espaço-temporal de decápodes meroplanctônicos na baía da Babitonga, SC, Brasil. 2009. 62 f. Dissertação (Mestrado em Zoologia) - Universidade Federal do Paraná, Curitiba. 2009.

ARAUJO, H. F. O. de; RODRIGUES, R. C.; NISHIDA, A. K. Composição da avifauna em complexos estuarinos no estado da Paraíba, Brasil. Revista Brasileira de Ornitologia, São Leopoldo, v. 14 , n. 3, p. 249-259, 2006

BOERSMA, P. D.; CLARK, J. A.; HILLGARTH, N. Seabird conservation. In: SCHREIBER, E. A.;

BURGER, J. (Ed.). Biology of marine birds. Boca Raton: CRC Press, 2001. p. 558-579.

BROOKE, M. de. L. Manx shearwater chicks: seasonal, parental, and genetic influences on the chick's age and weight at fledging. The Condor, Albuquerque, v. 88, p. 324-327, 1986.

BOSTAN, N.; ASHRAF, M.; MUMTAZ, A. S.; AHMAD, I.; ASHRAF, M.; BOSTAN, N.; MUMTAZ, A. S. Diagnosis of heavy metal contamination in agro-ecology of Gujranwala, Pakistan using cattle egret (Bubulcus ibis) as bioindicator. Ecotoxicology, New York, v. 16, n. 2, p. 247-251, 2007.

BURGER, J.; M. GOCHFELD, M. Effects of chemicals and pollution on seabirds. In: SCHREIBER, E. A.; BURGER, J. (Ed.). Biology of marine birds. Boca Raton: CRC Press, 2001. p. 485-525.

COULSON, J. C. Colonial breeding in seabirds. In: SCHREIBER, E. A.; BURGER, J. (Ed.). Biology of marine birds. Boca Raton: CRC Press, 2001. p. 87-113

CREMER, M. J.; GROSE, A. V. Ocorrência de aves marinhas no 
estuário da baía da Babitonga, costa norte de Santa Catarina, sul do Brasil. Revista Brasileira de Ornitologia, São Leopoldo, v. 18, n. 3, p. 176-182, 2010.

DUSI, J. L.; DUSI, R. T. Ecological factors contributing to nesting failure in a heron colony. Wilson Bulletin, Beltsville, v. 80, n. 4, p. 458-466, 1968.

FINK, D. Caracterização das colônias de aves aquáticas na Baía da Babitonga e avaliação preliminar de sua contaminação. 2013. 92 f. Dissertação (Mestrado em Saúde e Meio Ambiente) Universidade Regional de Joinville, Joinville. 2013.

FINK, D.; GROSE, A. V.; REIS, T. C. P.; CREMER, M. J. Colônias reprodutivas de aves aquáticas na baía da Babitonga, litoral norte de Santa Catarina. In: CONGRESSO LATINO-AMERICANO DE CIÊNCIAS DO MAR, 14, 2011, Balneário Camboriú. Resumos... Balneário Camboriú: Colacmar, 2011.

FRANK, D.; BECKER, P. H. Body-mass and nest reliefs in Common Terns Sterna hirundoexposed to different feeding conditions. Ardea, Beuningen, v. 80, n. 1, p. 57-69, 1992.

FREDERICHY, P. C. Wading birds in the marine environment. In: SCHREIBER, E. A.; BURGER, J. (Ed.). Biology of marine birds. Boca Raton: CRC Press, 2001. p. 617-655.

FRISANCO, D. Variação temporal da comunidade de estágios iniciais de peixes na praia estuarina da desembocadura do rio da Pedreira, área portuária de São Francisco do Sul (baía da Babitonga) e a influência do meio. 2007. 36 f. Monografia (Bacharelado em Ciências Biológicas com Habilitação em Biologia Marinha) - Universidade da Região de Joinville, São Francisco do Sul. 2007

GIANUCA, D. Abundância e ecologia reprodutiva de Pelecaniformes em uma colônia na ilha dos marinheiros, estuário da Lagoa dos Patos, RS. 2010. 104 f. Dissertação (Mestrado em Oceanografia Biológica) - Universidade Federal do Rio Grande, Rio Grande. 2010.

GIANUCA, D.; COSTA, C. S. B. Expansão geográfica do socócaranguejeiro Nyctanassa violacea (Linnaeus, 1758): consequência de um aquecimento climático local? In: CONGRESSO DE ECOLOGIA DO BRASIL, 7, 2007, Caxambu. Anais... Caxambu: CEB, 2007. http://www.seb-ecologia.org.br/viiiceb/pdf/1571.pdf

GIANUCA, D.; GIANUCA, A. T.; VOOREN, C. M. Abundance, breeding and food of the Little Blue Heron Egretta caerulea (Aves, Ardeidae) in the Patos Lagoon estuary, a recently colonized area in southern Brazil. Iheringia, Série Zoologia, Porto Alegre, v. 102, n. 1, p. 19-25, 2012.

GREEN, A. J.; FIGUEROLA, J. Aves acuáticas como bioindicadores en los humedales. Instituto de Estudios Almerienses, Almería, Colección Actas, 49, p. 47-60, 2003.

GROSE, A. V. Reprodução de aves aquáticas na ilha do Maracujá, estuário da baía da Babitonga, litoral de Santa Catarina. 2012. 80 f. Dissertação (Mestrado em Zoologia) Universidade Federal do Paraná, Curitiba. 2012.

GROSE, A. V.; MOREIRA, N.; CREMER, M. J. Biologia reprodutiva do socó-caranguejeiro (Nyctanassa violacea) e socó-dorminhoco (Nycticorax nycticorax) no Estuário da baía da Babitonga, litoral sul do Brasil. In: CONGRESSO LATINOAMERICANO DE CIÊNCIAS DO MAR, 14, 2011, Balneário Camboriú. Resumos... Balneário Camboriú: Colacmar, 2011a. Versão eletrônica.
GROSE, A. V.; SOUZA, T. F; CREMER, M. J. Anilhamento de aves aquáticas no estuário da baía da Babitonga, São Francisco do Sul, Santa Catarina, Brasil. In: CONGRESSO LATINOAMERICANO DE CIÊNCIAS DO MAR. 14, 2011, Balneário Camboriú. Resumos... Balneário Camboriú: Colacmar, 2011b. Versão eletrônica.

IBAMA. Proteção e controle de ecossistemas costeiros: manguezal da baía da Babitonga. Brasília: Edições IBAMA. 1998. $146 \mathrm{p}$.

JOLY, C. A.; ASSIS, M. A.; BERNACCI, L. C.; TAMASHIRO, J. Y.; CAMPOS, M. C. R.; GOMES, J. A. M. A.; LACERDA, M. S.; SANTOS, F. A. M.; PEDRONI, F.; PEREIRA, L. S.; PADGURSCHI, M. C. G.; PRATA, E. M. B.; RAMOS, E.; TORRES, R. B.; ROCHELLE, A.; MARTINS, F. R.; ALVES, L. F.; VIEIRA, S. A.; MARTINELLI, L. A.; CAMARGO, P. B.; AIDAR, M. P. M.; EISENLOHR, P. V.; SIMÕES, E.; VILLANI, J. P.; BELINELLO, R. Florística e fitossociologia em parcelas permanentes da Mata Atlântica do sudeste do Brasil ao longo de um gradiente altitudinal. Biota Neotropica, Campinas, v. 12, n. 1, p. 123-145, 2012.

JOSENS, M. L.; PRETElli, M. G.; ESCALANTE, A. H.; JOSENS, M. L.; PRETELLI, M. G. Censos de aves acuáticas en sus colonias reproductivas en lagunas del sudeste de la provincia de Buenos Aires. Hornero, Buenos Aires, v. 24, n. 1, p. 7-12, 2009.

KUSHLAN, J. A.; HANCOCK, J. A. The herons. Oxford: Oxford Academic Press, 2005. 433 p.

MATOS, R. H. R. Biologia comportamental de Nyctanassa violacea (Linnaeus, 1758) Ciconiiformes, Ardeidae: reprodução e alimentação na ilha do Cajual, Alcântara, Maranhão. 1996. 85 f. Dissertação (Mestrado em Ciências Biológicas) - Universdade Estadual Paulista, Rio Claro. 1996.

NELSON, J. B.; BAIRD, P. H. Seabird communication and displays, In: SCHREIBER, E. A.; BURGER, J. (Ed.). Biology of marine birds. Boca Raton: CRC Press, CRC Marine Biology, 2001. p. 307-357.

O'CONNOR, R. J. Brood reduction in birds: selection for fratricide, infanticide and suicide? Animal Behavior, Bloomington, v. 26, n. 1, p. 79-96, 1978.

OLIVEIRA, T. M. N. de; TURECK, C. R.; BASSFELD, J. C.; TORRENS, B. M. de O.; FARIA, J. M. Brasil. Integridade ambiental da baía da Babitonga: características físico-químicas, microbiológicas e ecotoxicidade. In: CREMER, M. J.; MORALES, P. R. D.; OLIVEIRA, T. M. N. (Ed.). Diagnóstico ambiental da baía da Babitonga. Joinville: UNIVILLE, 2006. 256 p.

OLMOS, F.; SILVA e SILVA, R. Breeding biology of the little blue heron (Egretta caerulea) in Southeastern Brazil. Ornitologia Neotropical, Montreal, v. 13, p. 17-30, 2002.

OLMOS, F.; SILVA e SILVA, R. Guará: ambiente, flora e fauna dos manguezais de Santos-Cubatão. São Paulo: Empresa das Artes, 2003. 216 p.

OLMOS, F.; SILVA e SILVA, R.; PRADO, A. Breeding season diet of scarlet ibises and little blue herons in a brazilian mangrove swamp. Waterbirds, Waco, v. 24, n. 1, p. 50-57, 2001.

PERIQUITO, M. C.; PEREIRA, G. A.; BRITO, M. T. de. Aves no manguezal do Espaço Ciência, Olinda, Pernambuco. Atualidades Ornitológicas On-line, Ivaiporã, n. 145, sem paginação, 2008.

POOLE, A. The effects of human disturbance on Osprey 
reproductive success. Waterbirds, Waco, v. 4, p. 20-27,. 1981.

RECHETELO, J. Biologia reprodutiva e dieta do socó-domangue, Nyctanassa violacea, no Parque Natural Municipal do Manguezal do Rio Perequê, no estado do Paraná, Brasil. 2009. 108 f. Dissertação (Mestrado em Ciências) - Universidade Federal do Paraná, Pontal do Sul. 2009.

RICKLEFS, R. E. A economia da natureza. Rio de Janeiro: Guanabara Koogan. 2003. 470 p.

SALVI, F. I. Biologia do caraguejo arborícola Aratus pisonii (H. Milne Edwards, 1837) (Crustacea, Brachyura, Grapsidae) os maguezais de Iguape, SP. 2002. 28 f. Monografia (Bacharelado em Ciências Biológicas) - Universidade do Oeste de Santa Catarina, Chapecó. 2002.

SICK, H. Ornitologia brasileira. Rio de Janeiro: Nova Fronteira, 2001. 862 p.

SILVA e SILVA, R.; OLMOS, F. Adendas e registros significativos para a avifauna dos manguezais de Santos e Cubatão, SP. Revista Brasileira de Ornitologia, São Leopoldo, v. 15, n. 4, p. 551-560, 2007.
SILVA, C. J. da; ABDO, M. S. A.; OLIVEIRA, D. M. M. de; GIRARD, P. Caraterização ambiental do ninhal Corutuba, Pantanal de Barão de Melgaço, MT. In: SIMPÓSIO SOBRE RECURSOS NATURAIS E SÓCIO-ECONÔMICOS DO PANTANAL, 3, 2000, Corumbá. Anais... Corumbá: UFMT, 2000. Versão eletrônica.

SILVA, E. M. da. Comportamento social e territorialidade alimentar na Garça-azul, Egretta caerulea (L.). 2008. 106 f. Dissertação (Mestrado em Psicobiologia) - Universidade Federal do Rio Grande do Norte, Natal. 2008.

WARNOCK, N.; ELPHICK, C.; RUBEGA, M. A. Shorebirds in marine environment. In: SCHREIBER, E. A.; BURGER, J. (Ed.). Biology of marine birds. Boca Raton: CRC Press, CRC Marine Biology, 2001. p. 581-615.

WIENS, J. A. The ecology of bird communities: foundations and patterns. Vol. 1. Cambridge: Cambridge University Press, 1989. $529 \mathrm{p}$.

WUNDERLICH, A. C.; PINHEIRO, M. A. A.; RODRIGUES, A. M. T. Biologia do caranguejo-uçá, Ucides cordatus (Crustacea: Decapoda: Brachyura), na Baía da Babitonga, Santa Catarina, Brasil. Revista Brasileira de Zoologia, Curitiba, v. 25 n. 2, p. 188198, 2008 